See Article page 2070.

\section{Commentary: Complete or incomplete? Just use more arteries}

\author{
Rodolfo V. Rocha, MD, Derrick Y. Tam, MD, and \\ Stephen E. Fremes, MD, MSc, FRCSC
}

One of the unique advantages of coronary artery bypass surgery $(\mathrm{CABG})$ is the potential to decrease future myocardial infarction, not only by bypassing flow-limiting coronary lesions identified in angiography, but also by protecting a distal myocardial territory that could become ischemic by an eventual rupture and thrombosis of non-flow-limiting lesions from the proximal third of the bypassed vessel. ${ }^{1}$ Hence, as Jones and Weintraub from Emory earlier mentioned in their landmark study evaluating completeness of coronary revascularization: "in the absence of a compelling technical limitation complete or nearly complete revascularization should be attempted with coronary operation." ${ }^{2}$ Besides completeness of revascularization, another strategy has been associated with improved long-term outcomes in CABG: the use of multiple arterial grafts (MAGs) instead of single arterial grafts (SAGs). ${ }^{3}$

In the current study, Rosenblum and colleagues ${ }^{4}$ investigated which of the 4 CABG strategies would be associated with better outcomes (MAG or SAG with or without complete revascularization) using inverse probability of treatment weighting (IPTW) to address baseline imbalances. At a median follow-up of 1366 days, MAG was associated with improved mid-term survival compared with SAG, regardless of completeness of revascularization.

The authors need to be congratulated for evaluating the unanswered question: "What is better for CABG patients: MAG or complete revascularization? Or both?" Nonetheless, this question is not easy to answer. Completeness of

\footnotetext{
From the Division of Cardiac Surgery, Department of Surgery, Schulich Heart Centre, Sunnybrook Health Sciences Centre, University of Toronto, Toronto, Ontario, Canada.

Disclosures: Authors have nothing to disclose with regard to commercial support.

Dr Tam is supported by the Ontario Ministry of Health Clinician Investigator's Program (Toronto, Ontario). Dr Fremes is supported by the Bernard S. Goldman Chair in Cardiovascular Surgery (Toronto, Ontario).

Received for publication Dec 4, 2019; revisions received Dec 4, 2019; accepted for publication Dec 4, 2019; available ahead of print Dec 24, 2019.

Address for reprints: Stephen E. Fremes, MD, MSc, FRCSC, Schulich Heart Centre, Sunnybrook Health Sciences Centre, 2075 Bayview Ave, Room H4 05, Toronto, Ontario, M4N 3M5, Canada (E-mail: stephen.fremes@sunnybrook.ca).

J Thorac Cardiovasc Surg 2021;161:2079-80

$0022-5223 / \$ 36.00$

Copyright (C) 2019 by The American Association for Thoracic Surgery

https://doi.org/10.1016/j.jtcvs.2019.12.028
}

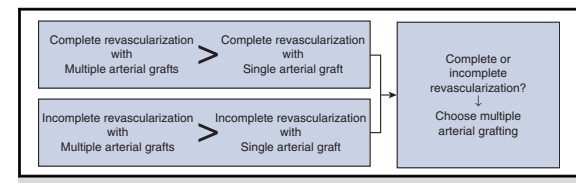

The use of arterial grafts is ideal regardless of completeness of revascularization.

\section{CENTRAL MESSAGE \\ Multiple arterial grafting and completeness of revasculariza- tion are 2 main pillars of improved outcomes in coronary artery bypass grafting.}

revascularization is not a parameter that is simple to measure. There have been multiple attempts to define what constitutes a complete revascularization procedure: ratio between number of diseased vessels and number of bypasses, number diseased of coronary territories divided by number of revascularized territories (complete numeric revascularization) or revascularization of only areas with ischemic myocardium, not bypassing areas with no viable myocardium (complete functional revascularization). ${ }^{2,5-7}$ Despite multiple proposed definitions, there is no clearly accepted criteria to determine completeness of revascularization. In addition, the reasons for incomplete revascularization in any individual patient are multifactorial (patients' instability, small targets, calcified coronaries, intramyocardial vessels, lack of conduits) and generally not well described, even in single-institutional reports with otherwise high-level data granularity.

The main advantage of using IPTW for baseline characteristics adjustment is the ability to calculate the average treatment effect using the entire data (unlike propensity score matching). To estimate the average treatment effect using IPTW, it is imperative that the population analyzed could undergo any of the 4 types of therapy. However, there was likely an important reason that patients who had incomplete revascularization did not get complete revascularization. Furthermore, the surgical strategy for the use of bilateral internal thoracic artery grafting at their institution excludes patients who are at greater risk of sternal infection. Also, 4 different group comparisons performed. Perhaps a method to adjust for multiplicity (Bonferroni or false-discovery rate correction) could have been employed to minimize the chances of a false-positive result. 
In regards to the comparison between MAG and SAG, the overwhelming majority of observational data has associated MAG with better outcomes. ${ }^{8}$ Nonetheless, retrospective studies will never be able to fully adjust unmeasured confounders that influence the surgeon's subjective decision to perform one technique over another. ${ }^{9}$ When analyzing the Emory hospital results post-IPTW adjustment, the incidence of hospital death was similar in the MAG and SAG cohorts. Nonetheless, postoperative intra-aortic balloon pump rates were lower in MAG versus SAG. Likewise, intensive care unit time was statistically shorter in MAG versus SAG. The early postoperative benefits are unlikely related to biological superiority of a MAG approach but rather suggest a residual imbalance between MAG versus SAG might have persisted despite statistical adjustments and could confound the clinical outcomes comparison.

Finally, the investigators observed no survival difference between MAG with or without complete revascularization in their follow-up (hazard ratio, $1.04 ; 95 \%$ confidence interval, 0.77-1.40, $P=.80$ ). Perhaps, if the follow-up is extended up to 5 to 10 years, we would observe a difference. Nonetheless, we would like to emphasize that completeness of revascularization should always be pursued and performing MAG does not exempt the surgeon to attempt to revascularize all possible diseased coronary vessels/territories. A relevant message from this study, that might likely impact patient care, is that if a conservative "non-MAG" surgeon believes completeness of revascularization cannot be accomplished in their case, they should at least attempt using MAG for this specific patient population.

The importance of incomplete revascularization can only be determined in observational studies with very granular operative and angiographic data such as Rosenblum and colleagues' provocative and well-designed retrospective study. In contrast, questions such as the role of MAG versus SAG CABG revascularization can probably be answered in randomized studies such as ART (Arterial Revascularization Trial) and the ongoing ROMA (Randomized Comparison of the Clinical Outcome of Single Versus Multiple Arterial grafts) trial to appropriately evaluate this question. ${ }^{10,11}$

\section{References}

1. Doenst T, Haverich A, Serruys P, Bonow RO, Kappetein P, Falk V, et al. PCI and $\mathrm{CABG}$ for treating stable coronary artery disease: JACC review topic of the week. J Am Coll Cardiol. 2019;73:964-76.

2. Jones EL, Weintraub WS. The importance of completeness of revascularization during long-term follow-up after coronary artery operations. $J$ Thorac Cardiovasc Surg. 1996;112:227-37.

3. Rocha RV, Tam DY, Karkhanis R, Nedadur R, Fang J, Tu JV, et al. Multiple arterial grafting is associated with better outcomes for coronary artery bypass grafting patients. Circulation. 2018;138:2081-90.

4. Rosenblum JM, Binongo J, Wei J, Liu Y, Leshnower BG, Chen EP, et al. Priorities in coronary artery bypass grafting: is midterm survival more dependent on completeness of revascularization or multiple arterial grafts? J Thorac Cardiovasc Surg. 2021;161:2070-8.e6.

5. Bangalore S, Guo Y, Samadashvili Z, Blecker S, Hannan EL. Revascularization in patients with multivessel coronary artery disease and severe left ventricular systolic dysfunction: everolimus-eluting stents versus coronary artery bypass graft surgery. Circulation. 2016;133:2132-40.

6. Bell MR, Gersh BJ, Schaff HV, Holmes DR Jr, Fisher LD, Alderman EL, et al. Effect of completeness of revascularization on long-term outcome of patients with three-vessel disease undergoing coronary artery bypass surgery. A report from the coronary artery surgery study (CASS) registry. Circulation. 1992;86:446-57.

7. Ong AT, Serruys PW. Complete revascularization: coronary artery bypass graft surgery versus percutaneous coronary intervention. Circulation. 2006;114: 249-55.

8. Yi G, Shine B, Rehman SM, Altman DG, Taggart DP. Effect of bilateral internal mammary artery grafts on long-term survival: a meta-analysis approach. Circulation. 2014;130:539-45.

9. Gaudino M, Di Franco A, Rahouma M, Tam DY, Iannaccone M, Deb S, et al. Unmeasured confounders in observational studies comparing bilateral versus single internal thoracic artery for coronary artery bypass grafting: a meta-analysis. J Am Heart Assoc. 2018;7:e08010.

10. Gaudino M, Alexander JH, Bakaeen FG, Ballman K, Barili F, Calafiore AM, et al. Randomized comparison of the clinical outcome of single versus multiple arterial grafts: the ROMA trial-rationale and study protocol. Eur J Cardiothorac Surg. 2017;52:1031-40.

11. Taggart DP, Benedetto U, Gerry S, Altman DG, Gray AM, Lees B, et al. Bilateral versus single internal-thoracic-artery grafts at 10 years. N Engl J Med. 2019;380: $437-46$. 